\title{
Simultaneously Enhanced Mechanical Properties and Damping Capacities of ZK60 Mg Alloys Processed by Multi-Directional Forging
}

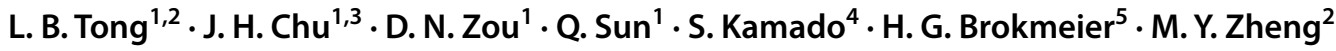

Received: 1 July 2020 / Revised: 16 July 2020 / Accepted: 18 July 2020 / Published online: 19 September 2020

(c) The Chinese Society for Metals (CSM) and Springer-Verlag GmbH Germany, part of Springer Nature 2020

\begin{abstract}
In this study, the mechanical properties and damping capacities of cast $\mathrm{Mg}-5.5 \mathrm{Zn}-0.6 \mathrm{Zr}$ (weight percent, ZK60) alloys have been simultaneously improved by a facile multi-directional forging (MDF) processing, and the mechanisms of microstructure evolution and texture modification are systematically investigated. The activation of tension twinning occurs during the initial MDF stage, due to the coarse-grained structure of the as-cast alloy. With increasing MDF passes, the continuous dynamic recrystallization (CDRX) results in a fine equiaxed-grain structure. The typical non-basal texture is formed in the as-MDFed alloy for 6 passes, with the (0001) planes inclined $60^{\circ}-70^{\circ}$ to forged direction and $10^{\circ}-20^{\circ}$ to transverse direction, respectively. A good balance between the strength ( 194.9 MPa) and ductility $(\sim 24.9 \%)$ has been achieved, which can be ascribed to the grain refinement, non-basal texture and fine precipitate particles. The damping capacity is remarkably improved after MDF processing, because the severe deformation increases the dislocation density, which effectively enlarges the sweep areas of mobile dislocations.
\end{abstract}

Keywords Mg alloy $\cdot$ Multi-directional forging $\cdot$ Microstructure $\cdot$ Texture evolution $\cdot$ Mechanical properties $\cdot$ Damping capacity

\section{Introduction}

In recent years, magnesium $(\mathrm{Mg})$ and its alloys have attracted much concern in the aerospace, automobile, biomedical and defense industries, because of their low density,

Available online at https://link.springer.com/journal/40195.

L. B. Tong

lbtong@xauat.edu.cn

$\triangle$ M. Y. Zheng

zhenghe@hit.edu.cn

1 School of Metallurgical Engineering, Xi' an University of Architecture and Technology, Xi' an 710055, China

2 School of Materials Science and Engineering, Harbin Institute of Technology, Harbin 150001, China

3 College of Materials Science and Engineering, Jilin University, Changchun 130025, China

4 Department of Mechanical Engineering, Nagaoka University of Technology, Nagaoka 940-2188, Japan

5 Institute of Materials Science and Engineering, Clausthal University of Technology, Agricolastrasse 6, 38678 Clausthal-Zellerfeld, Germany high strength-weight ratio, superior damping capacity and biocompatibility [1-3]. Unfortunately, the poor ductility severely restricts the workability of $\mathrm{Mg}$ alloy, due to its dense-hexagonal structure. Therefore, $\mathrm{Mg}$ alloy is usually considered as one of the typical "difficult to work" metallic materials $[4,5]$. Moreover, the relatively low strength of $\mathrm{Mg}$ alloys compared with the steels, Ti or Al alloys also hinders their wide range of industrial applications [6, 7]. The microalloying ( $\mathrm{Al}, \mathrm{Zn}, \mathrm{Ca}$ or $\mathrm{Mn}$ ) and thermomechanical processing (such as extrusion, rolling or forging) can remarkably improve the mechanical properties of $\mathrm{Mg}$ alloys, through the elimination of casting defects, grain refinement and texture modification [8-11]. Unfortunately, the alloying elements have been proved to deteriorate the damping capacities of $\mathrm{Mg}$ alloys, because the solid solution atoms, grain boundaries or fine precipitates will result in the intensive pinning effects for dislocation movements [12-14]. Therefore, how to simultaneously improve the mechanical properties and damping performances of $\mathrm{Mg}$ alloys has become a worldwide hot topic.

Severe plastic deformation (SPD) technique can achieve an ultra-fine grained (UFG) structure, among which the multi-directional forging (MDF) is facile (using 
conventional processing equipment) to fabricate the largescale $\mathrm{Mg}$ alloy components, exhibiting a great potential in the engineering applications, compared with the equal channel angular pressing (ECAP), high pressure torsion (HPT) and accumulative roll bonding (ARB) [15-18]. High accumulated strains during the reduplicative MDF processing will lead to the dynamic recrystallization behavior in $\mathrm{Mg}$ alloys, which is beneficial to the improvement of mechanical properties through grain refinement, texture evolution or precipitation strengthening effect. Moreover, the characteristic rotation mode during the MDF processing can effectively restrict the formation of intensive basal texture and reduce the anisotropy of mechanical properties of $\mathrm{Mg}$ alloys [19, 20].

The plastic deformation abilities of $\mathrm{Mg}-\mathrm{Zn}$ series alloys are much lower than that of $\mathrm{Mg}-\mathrm{Al}$ series alloys, because $\mathrm{Zn}$ element easily leads to the grain coarsening effect and hot cracking tendency. Therefore, the as-cast $\mathrm{Mg}-\mathrm{Zn}$ alloys are difficult to directly work through MDF processing. Many studies have reported the influences of MDF on the microstructure, texture evolution and mechanical properties of wrought $\mathrm{Mg}-\mathrm{Zn}$ alloys, due to their fine-grained microstructure and improved workability [21, 22]. In addition, the restriction of dislocation motion generally contributes to the increased strength of $\mathrm{Mg}$ alloy, but easily reduces its damping performance $[23,24]$. Therefore, there exists an intrinsic contradiction between the mechanical property and damping capacity. However, the influences of MDF processing on the damping behaviors of $\mathrm{Mg}-\mathrm{Zn}$ series alloys have rarely reported.

In the current study, the commercial as-cast ZK60 alloy after homogenization treatment is successfully processed through MDF at $300{ }^{\circ} \mathrm{C}$. The main purpose is to clarify the influence mechanisms of the microstructure and texture evolution during the MDF process on the mechanical properties and damping behaviors of ZK60 alloys, which will pave a new avenue for the processing technology of high-performance $\mathrm{Mg}$ alloys in the future.

\section{Experimental}

The ZK60 alloy with nominal Mg-5.5Zn-0.6Zr (wt\%) alloy was fabricated using pure $\mathrm{Mg}, \mathrm{Zn}$ and $\mathrm{Mg}-3.0 \mathrm{Zr}$ (wt\%) master alloy, through the conventional gravity casting. The as-cast alloy was homogenized at $420{ }^{\circ} \mathrm{C}$ for $18 \mathrm{~h}$, and then machined into the billets with dimensions of $30 \mathrm{~mm} \times 30 \mathrm{~mm} \times 60 \mathrm{~mm}$ using the wire-electrode cutting. The microstructures of as-cast and as-homogenized alloys are shown in Fig. 1a and b, with the average grain size of $\sim 130 \mu \mathrm{m}$ and $\sim 200 \mu \mathrm{m}$, respectively. Many secondary phases with dark contrast were distributed on the grain boundaries of as-cast alloy, which were almost fully dissolved into $\alpha-\mathrm{Mg}$ matrix after homogenization treatment. The multi-pass MDF processing was carried out at $300{ }^{\circ} \mathrm{C}$, with its ram speed of $2.0 \mathrm{~mm} / \mathrm{s}$ and equivalent strain of 0.8
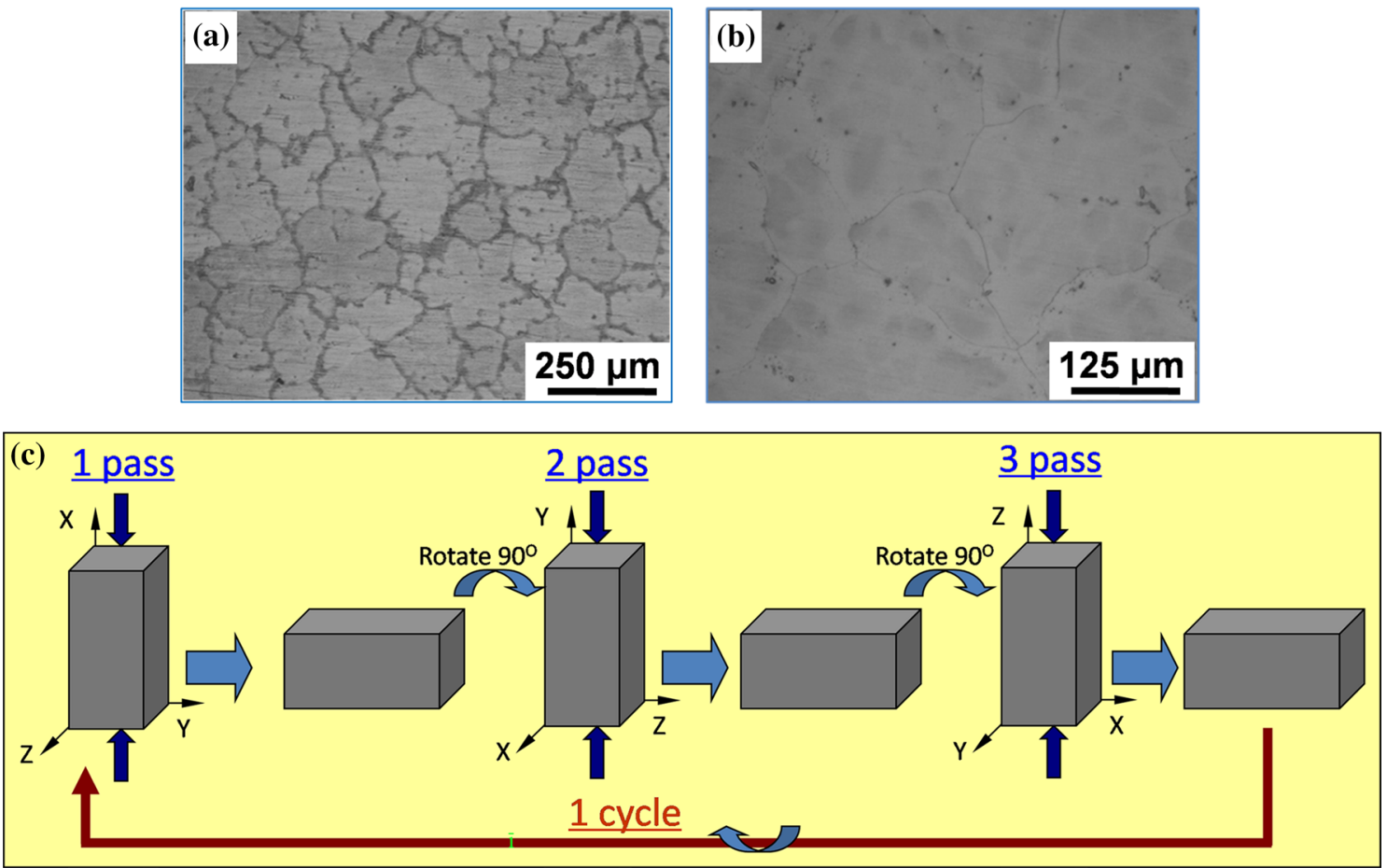

Fig. 1 OM microstructures of the $\mathbf{a}$ as-cast $\mathbf{b}$ as-homogenized alloys, $\mathbf{c}$ sketch map of MDF process 
for each pass. The schematic diagram for the rotation direction and shape evolution is shown in Fig. 1c, and the samples experienced the whole circulation for every 3 passes.

The microstructures of all the samples were observed using an Olympus optical microscope (OM), a Hitachi S-4800 filed emission scanning electron microscope (FESEM), equipped with an electron backscattered diffraction (EBSD, TSL MSC-2200), and a Philips-CM12 transmission electron microscope (TEM) operating at $200 \mathrm{kV}$. The EBSD samples were initially ground using metallographic sandpaper from 600 to 2000, and then polished by a Struers Rotopol-15 automatic polishing machine using polishing suspension OP-S ( $\sim 04 \mu \mathrm{m}$ sized $\mathrm{SiO}_{2}$ particles). The average grain size was calculated using Image-Pro Plus 5.0 software, with more than 800 grains for each sample. The global texture was analyzed by the neutron diffractometer TEX-2 in GKSS Forschungszentrum Geesthacht.

The room-temperature mechanical properties of ZK60 alloys were measured using an Instron 5569, with three trials for each sample to reduce the deviation. The dog-bone shaped samples were machined along the longitudinal planes (perpendicular to forged direction, FD), with the gauge length of $10.0 \mathrm{~mm}$. The fractographic surface observation was carried out on the S-4800 FE-SEM, in order to demonstrate the fracture mechanism. The damping behaviors were measured by dynamic mechanical analyzer (DMA, Q800) with a single cantilever mode. Strain amplitude dependence of damping capacity was measured at ambient temperature from $10^{-5}$ to $10^{-3}$, with its vibration frequency of $0.5 \mathrm{~Hz}$. Damping capacity versus temperature curves were measured from 25 to $400{ }^{\circ} \mathrm{C}$, with a fixed strain amplitude of $4.0 \times 10^{-5}$.

\section{Results}

\subsection{Microstructure}

Figure 2 shows the microstructure evolution of the ashomogenized ZK60 alloy after the MDF processing. Except for a large number of dynamic recrystallized (DRX) fine grains with the average grain size of $5.0 \mu \mathrm{m}$, some coarse unDRX grains (shown by red arrows) can be observed within the as-MDFed alloy after 1 pass, exhibiting a typically bimodal grain size distribution. With increasing MDF passes, the grain refinement effect is remarkably enhanced, and the average grain size is decreased to $4.2 \mu \mathrm{m}$ and $3.0 \mu \mathrm{m}$ in the as-MDFed alloys for 3 and 6 passes, respectively. The volume fraction of DRX grain is dramatically increased to $\sim 90 \%$ in the as-MDFed alloy for 6 passes, representing
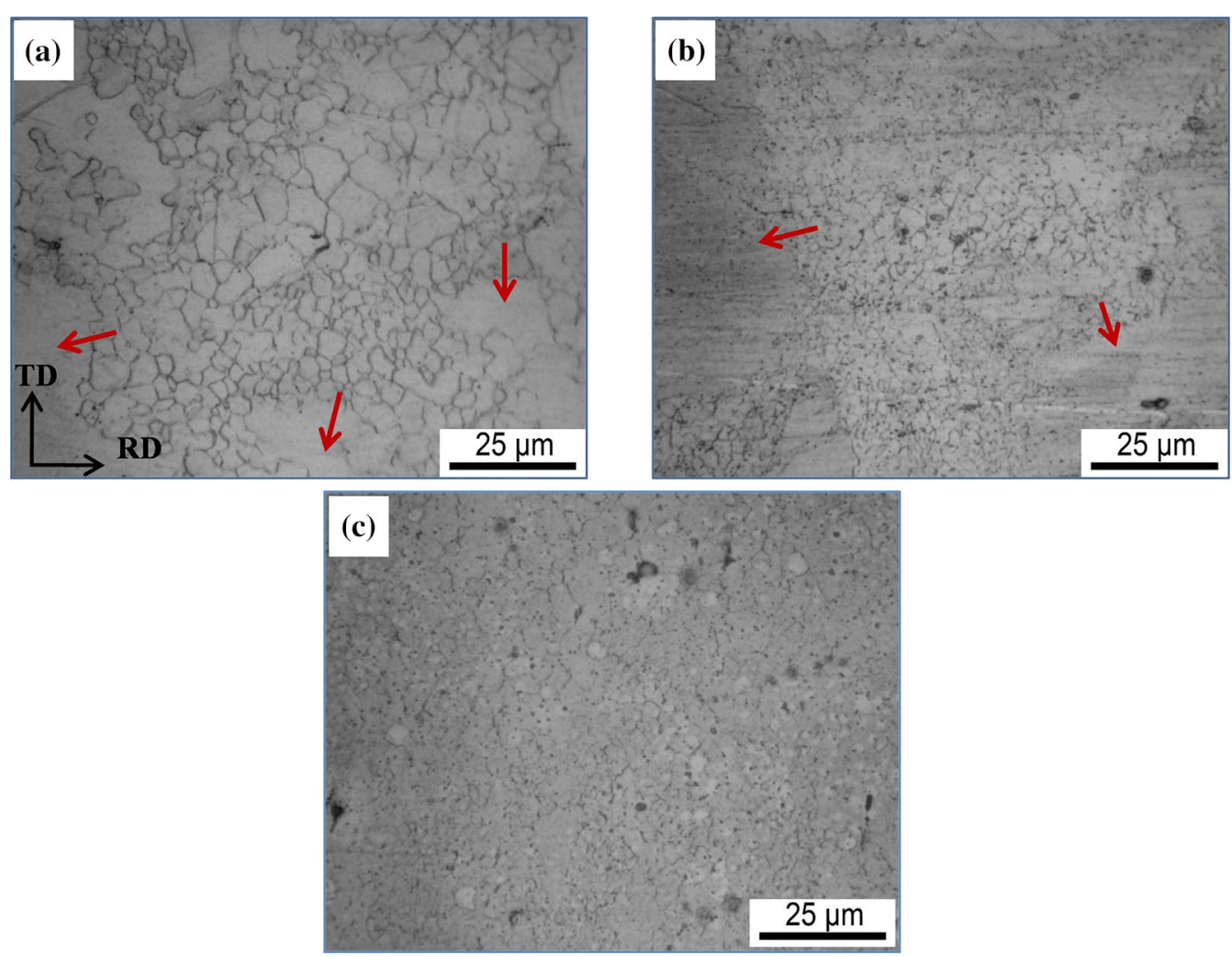

Fig. 2 OM micrographs of the as-MDFed alloys for a 1 pass, b 3 passes $\mathbf{c} 6$ passes 
a fully recrystallization process. In addition, the number of fine secondary phase particle is increased with increasing MDF passes, which is related to the dynamic precipitation effect.

In order to further investigate the detailed constitution and morphology of secondary phase particles, Fig. 3 shows TEM micrographs of as-MDFed alloy after 6 passes. The equiaxed grain microstructure is observed (Fig. 3a), within which there are some dislocations (shown by red arrows) and many fine secondary phase particles $(10-100 \mathrm{~nm})$. The selected area electron diffraction (SAED) proves that these particles are $\mathrm{MgZn}_{2}$ (Fig. $3 \mathrm{~b}$ and c), which has been widely reported in the previous studies [25, 26]. The appearance of fine $\mathrm{MgZn}_{2}$ phase is related to the dynamic precipitation during the reduplicative MDF process, because the homogenization treatment easily results in the supersaturation state of $\mathrm{Zn}$ elements in $\alpha-\mathrm{Mg}$ matrix. These fine precipitates are beneficial to the pinning effect for grain growth and contribute to the grain refinement effect.
Figure 4 shows the orientation image microscopy (OIM) of as-MDFed alloys after different passes, and the red, green and blue colors imply the orientations of $\langle 0001\rangle,\langle\overline{1} 2 \overline{1} 0\rangle$ and $\langle 01 \overline{1} 0\rangle$ crystallographic directions parallel to FD, respectively. Many coarse unDRX grains are observed in the asMDFed alloy for 1 pass, within which the $\{10 \overline{1} 2\}\langle 10 \overline{1} 1\rangle$ twinning (tension twining) activation behavior (proved by its misorientation angle analysis of grain boundaries) occurs to coordinate the large deformation (Fig. 4a). Some fine grains are embedded inside the coarse deformed grains, which are related to the DRX process during the MDF. A large number of grain boundaries with orientation angle of $2^{\circ}-4^{\circ}$ (shown by white lines) can be observed in the unDRX grains, implying that the DRX process is not completed. With further MDF processing, the average DRX grain size is decreased, and their volume fractions are gradually increased. Especially for the as-MDFed alloy after 6 passes, the twinning activation behaviors and coarse unDRX grains

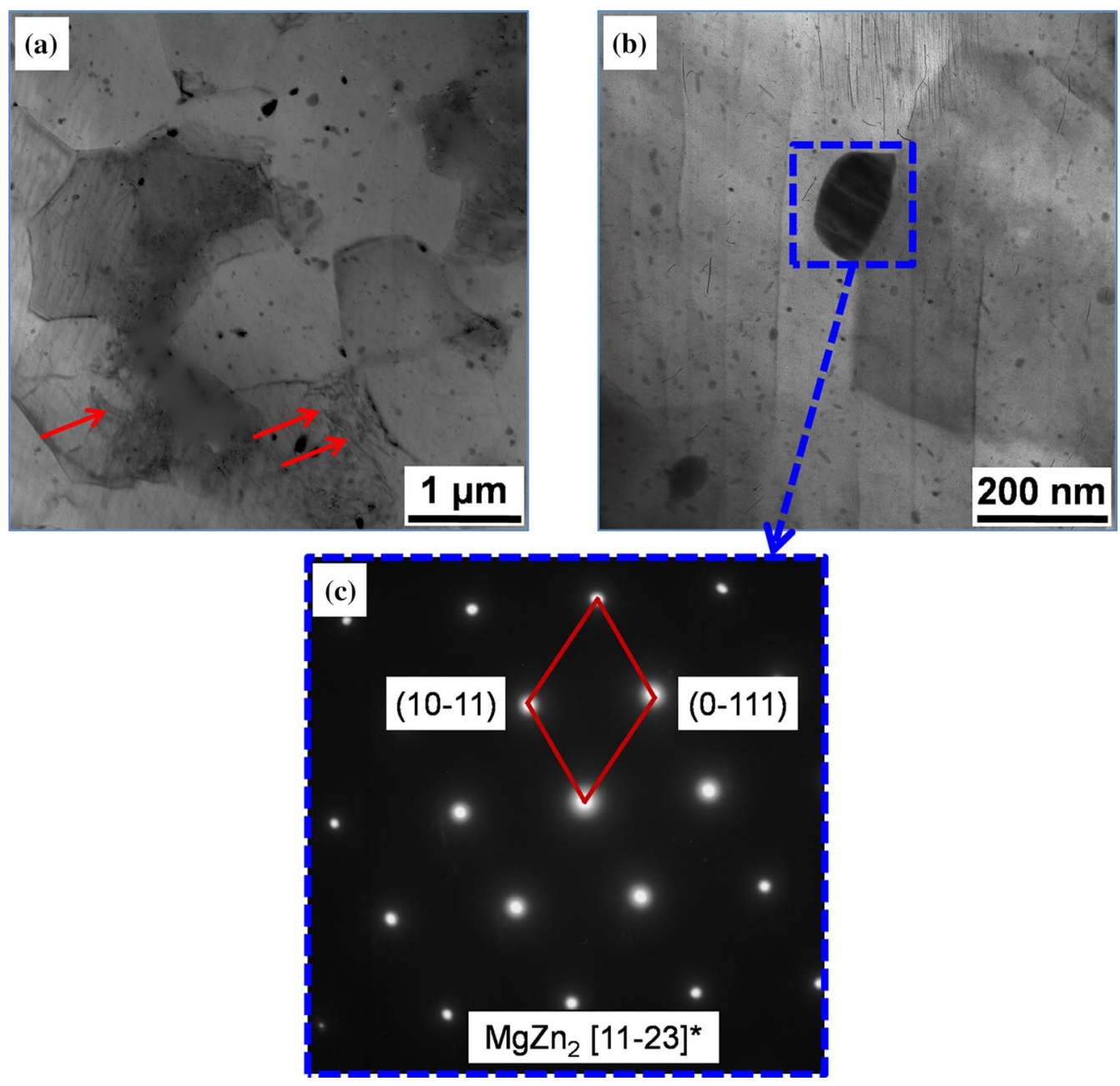

Fig. 3 TEM micrographs of the as-MDFed alloy for 6 passes: a grain morphologies, $\mathbf{b}$ enlargement of fine precipitate particles $\mathbf{c}$ SAED of blue dash line region 

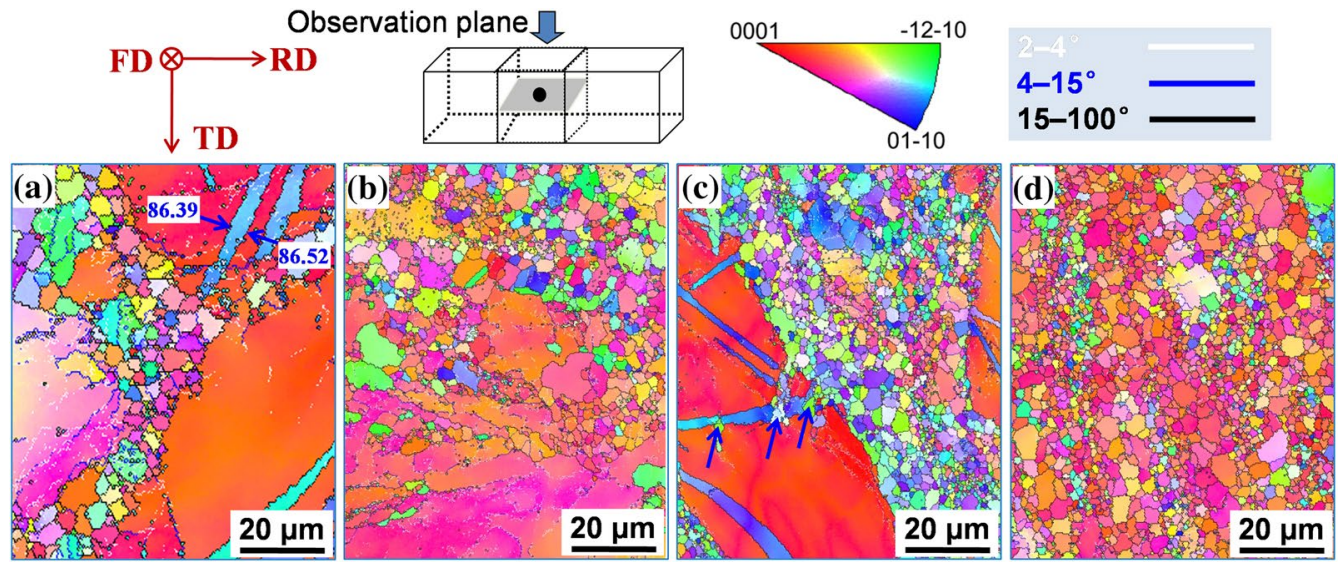

Fig. 4 OIM micrographs of the as-MDFed alloys for a 1 pass, $\mathbf{b} 2$ passes, $\mathbf{c} 3$ passes $\mathbf{d} 6$ passes, and the reference direction is FD

are hardly observed, representing a completed DRX process, which is accordance with the OM results.

Figure 5 shows the evolution of misorientation angle of ZK60 alloys after the MDF processing, and the corresponding data are calculated. The volume fractions of low-angle grain boundaries (LAGBs) are calculated as $34.2 \%, 32.3 \%$, $28.1 \%$ and $17.6 \%$ in the as-MDFed alloys for $1,2,3$ and 6 passes, respectively. The linear decrease in LAGBs with increasing accumulated strains indicates that the dynamic recrystallization process is gradually completed, which leads

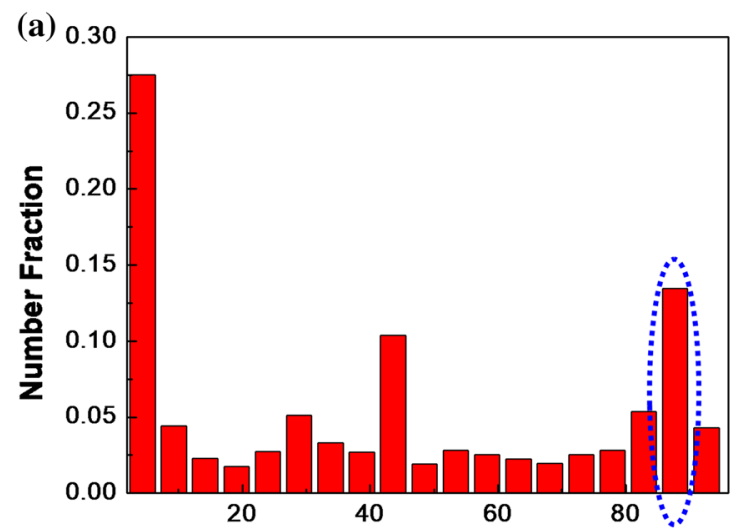

Misorientation Angle (degrees)

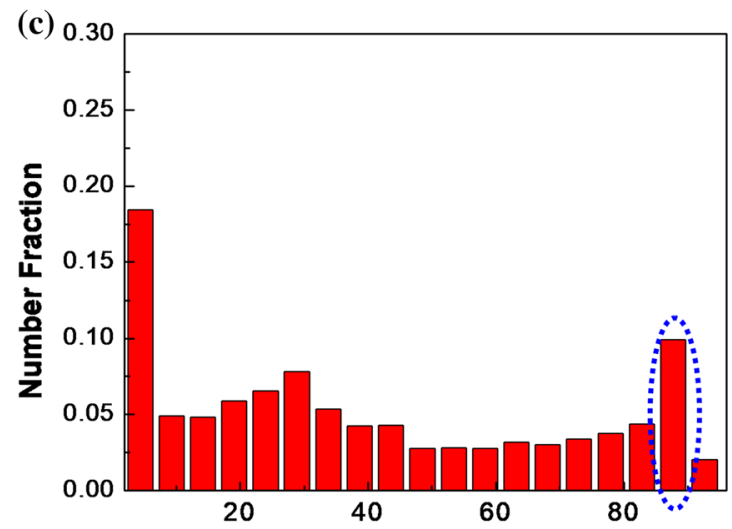

Misorientation Angle (degrees)

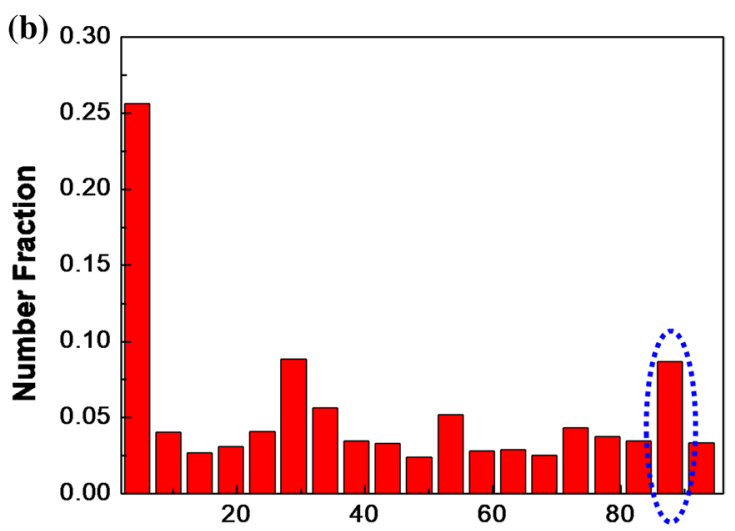

Misorientation Angle (degrees)

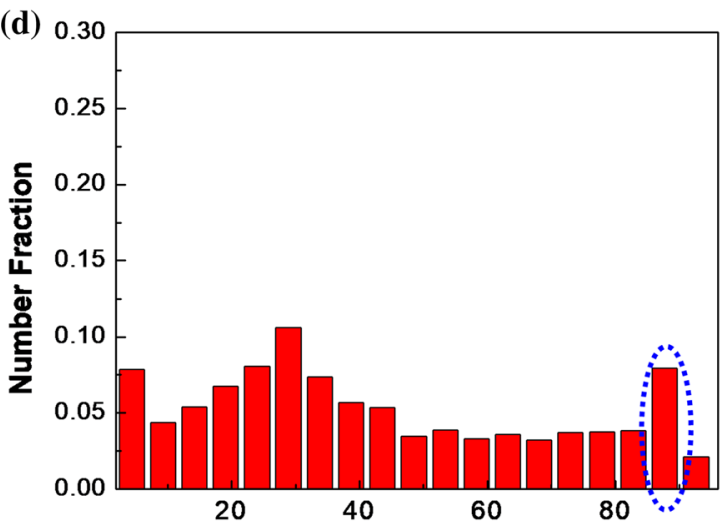

Misorientation Angle (degrees)

Fig. 5 Misorientation angle distribution of the as-MDFed alloys for a 1 pass, $\mathbf{b} 2$ passes, $\mathbf{c} 3$ passes $\mathbf{d} 6$ passes 
to a remarkable grain refinement effect and will contribute to the improvement of the mechanical properties. Moreover, the volume fraction of specific misorientation angle $\left(85.8^{\circ}-89.7^{\circ}\right.$, shown by blue dash line) is dramatically decreased with increasing MDF passes, implying that the twinning activation is seriously hindered.

\subsection{Texture Evolution}

Figure 6 shows the micro-texture evolution of the as-MDFed ZK60 alloys after different passes, through the EBSD analysis. An approximate basal texture, with the $\langle 0001\rangle$ direction inclining $0^{\circ}-10^{\circ}$ to $\mathrm{FD}$, can be observed in the as-MDFed alloy after 1 pass (shown by Position A). Moreover, there also exists the B-type texture, with the (0001) planes parallel to FD. Combined the inspection of the OIM (Fig. 4a) and texture evolution (Fig. 6a), the A and B texture components are related to the unDRX grains and tension twins (the misorientation angle between $\alpha-\mathrm{Mg}$ matrix and twin has been proved as $\sim 86.3^{\circ}$ rotation), respectively. In contrast, the fine DRX grains hardly exhibit the preferred orientation behavior. After MDF for 2 passes, the main texture component almost retains unchanged, while the intensity of which is remarkably increased. After 3 passes, the ZK60 alloy experiences a whole cycle (Fig. 1), a typical basal texture has been formed, with $\langle 0001\rangle$ crystallographic direction parallel to FD. Meanwhile, a weak non-basal texture component can be observed, with the (0001) planes inclined to $\sim 45^{\circ}$ and $\sim 30^{\circ}$ to $\mathrm{FD}$ and transverse direction (TD). With further deformation, the as-MDFed alloy after 6 passes represents a non-basal texture, with most of (0001) planes inclined $\sim 70^{\circ}$ to $\sim 15^{\circ} \mathrm{FD}$ and $\mathrm{TD}$, respectively. In addition, the corresponding texture intensity is dramatically weakened, which may be related to the recrystallization process and will be discussed in the following section.

Figure 7 shows the pole figures of the ZK60 alloys through the neutron diffraction analysis (global texture). The as-homogenized alloy exhibits a random texture distribution (Fig. 7a). For the as-MDFed alloy after 1 pass, most of grains exhibit a basal texture with their (0001) planes perpendicular to $\mathrm{FD}\left(80^{\circ}-90^{\circ}\right)$, which is in agreement with the EBSD results (Fig. 7b). However, the B-type texture (Fig. 6a) cannot be observed, because the volume fraction of tension twins is very low. The as-MDFed alloy after 3 passes represents a typical basal texture characteristic, with the (0001) planes perpendicular to FD. Moreover, a weak texture with basal planes parallel to TD and inclined to RD $40^{\circ}-90^{\circ}$ (Fig. 7c). With further MDF processing, the final non-basal texture has formed in the sample after 6 passes. The basal planes in most of grains are inclined about $60^{\circ}-70^{\circ}$ to $\mathrm{FD}$ and $10^{\circ}-20^{\circ}$ to $\mathrm{TD}$, except for a weak basal texture component with (0001) planes perpendicular to FD (Fig. 7d), which is in accordance with EBSD analysis.

\subsection{Mechanical Properties and Damping Behaviors}

Figure 8 shows the room-temperature tensile curves of the as-MDFed ZK60 alloys, and the corresponding mechanical properties are calculated in Table 1. Compared with that of the as-homogenized alloy, the tensile yield strength (TYS), ultimate tensile strength (UTS) and elongation to failure (EF) are remarkably improved in the as-MDFed alloys, regardless of the deformation passes. With the increase in plastic strains during MDF processing (from 1 to 3 passes), both TYS and UTS are monotonously increased. However, the TYS and UTS values of as-MDFed alloy after 6 passes are decreased to a certain degree, compared with that after

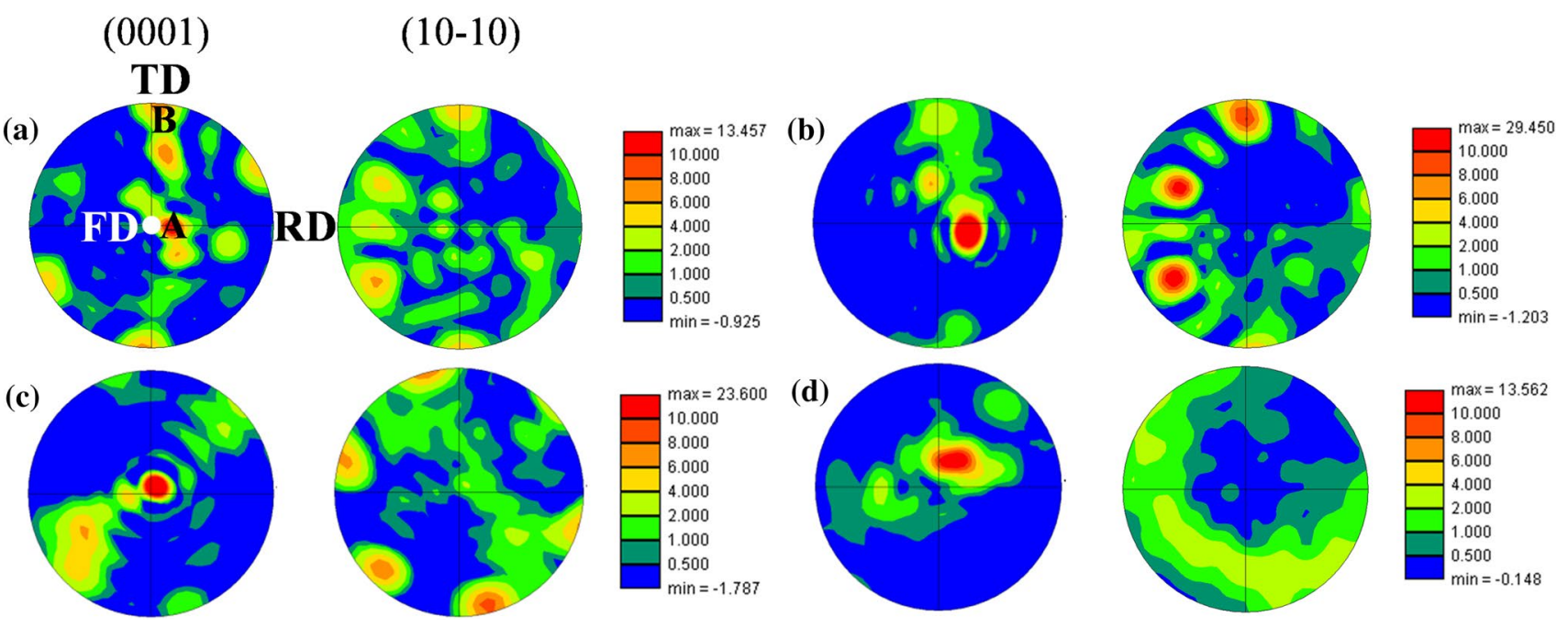

Fig. 6 Micro-texture analysis of the as-MDFed alloys for a 1 pass, $\mathbf{b} 2$ passes, $\mathbf{c} 3$ passes $\mathbf{d} 6$ passes 
(a)

\section{(0001) TD}

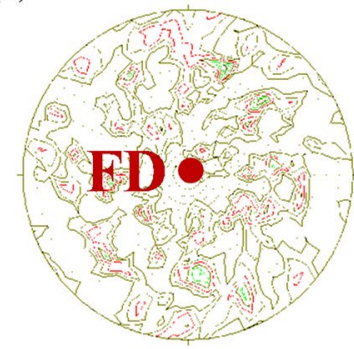

(b)

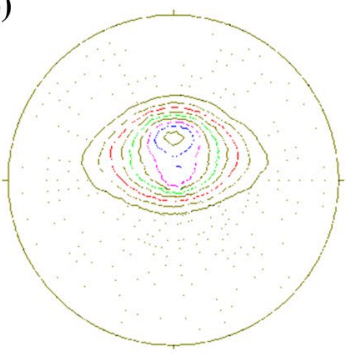

(c)

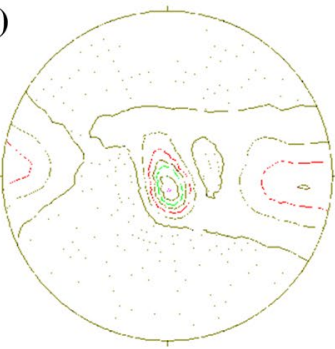

(d)

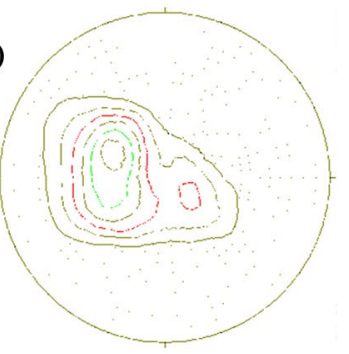

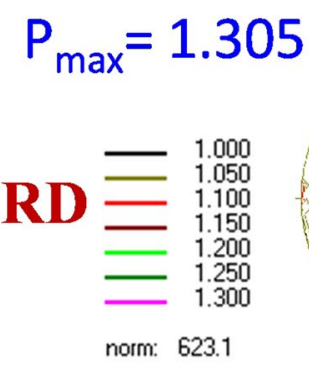

$P_{\max }=5.208$

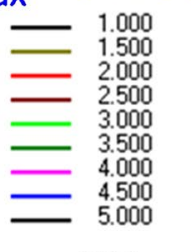

norm: 621.2

$P_{\text {max }}=4.059$
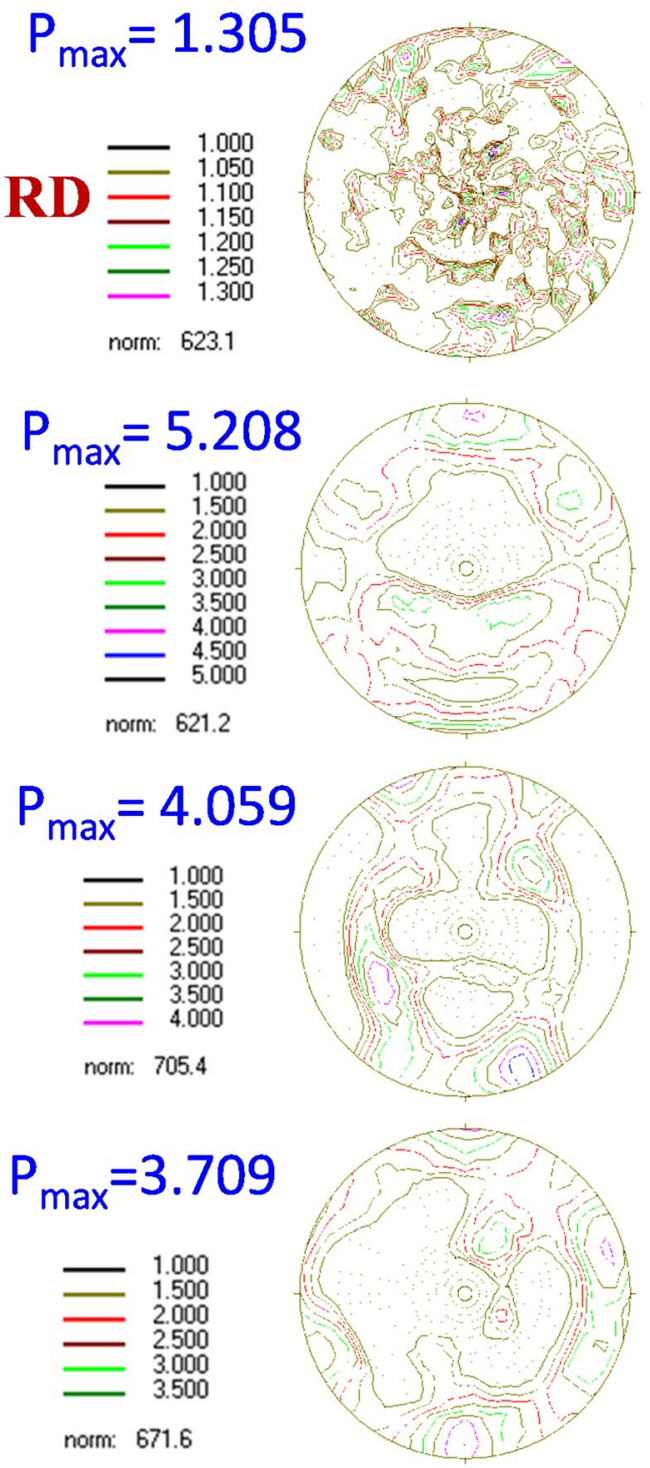

$(10-10)$
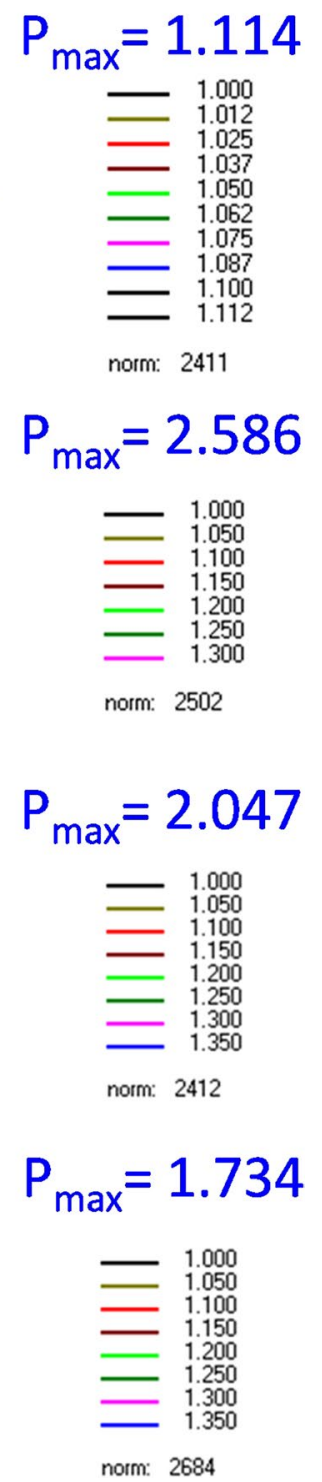

norm: 2684

Fig. 7 Pole figures of the a as-homogenized and as-MDFed alloys after $\mathbf{b} 1$ pass, $\mathbf{c} 3$ passes $\mathbf{d} 6$ passes

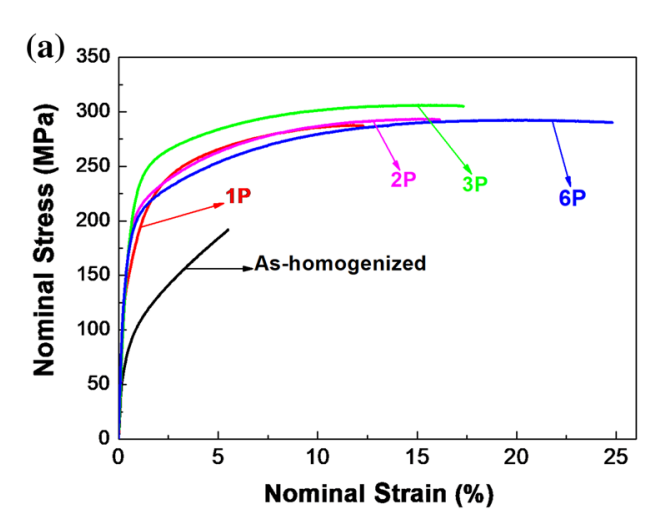

\footnotetext{
Fig. 7 Pole figures of the a as-homogenized and as-MDFed alloys after b 1 pass, $\mathbf{c} 3$ passes $\mathbf{d} 6$ passes
}

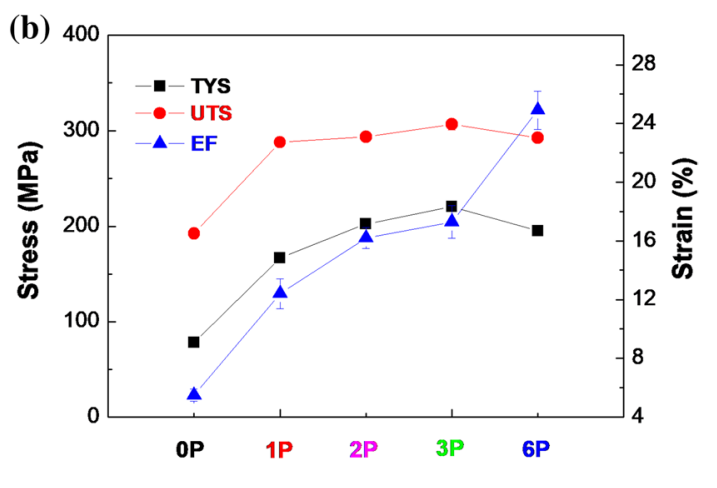

Fig. 8 Room-temperature mechanical properties of the as-MDFed alloys after different passes: $\mathbf{a}$ tensile curves $\mathbf{b}$ calculated data 
Table 1 Tensile property of ZK60 alloys after MDF processing for different passes

\begin{tabular}{lcrr}
\hline ZK60 alloys & UTS $(\mathrm{MPa})$ & TYS $(\mathrm{MPa})$ & \multicolumn{1}{c}{ EF $(\%)$} \\
\hline As-homogenized & $192.4 \pm 3.5$ & $78.1 \pm 2.1$ & $5.5 \pm 0.4$ \\
MDF-1P & $287.9 \pm 4.2$ & $166.6 \pm 1.9$ & $12.4 \pm 1.0$ \\
MDF-2P & $293.7 \pm 3.4$ & $202.5 \pm 4.2$ & $16.2 \pm 0.7$ \\
MDF-3P & $306.6 \pm 5.6$ & $220.5 \pm 2.8$ & $17.3 \pm 1.1$ \\
MDF-6P & $292.8 \pm 2.9$ & $194.9 \pm 3.1$ & $24.9 \pm 1.3$ \\
\hline
\end{tabular}

3 passes. In addition, the EF values of the as-MDFed alloys are gradually improved with increasing deformation pass, representing the outstanding ductility. A good balance between the strength and ductility has been achieved in the as-MDFed alloy for 6 passes, compared with that reported in the previous studies $[27,28]$, which may be related to its microstructure and texture evolution.

Figure 9 shows the damping behaviors of ZK60 alloys after MDF processing for different passes. As shown in Fig. 9a, the damping capacity value versus strain amplitude curves exhibit two distinct stages (strain-amplitude independent, $Q_{0}^{-1}$ and dependent, $\left.Q_{h}^{-1}\right)$, and the critical strain value is recognized as $\sim 3.0 \times 10^{-5}$, which is hardly influenced by MDF processing. The $Q_{0}^{-1}$ value is calculated as $0.0014,0.0014,0.0017$ and 0.0018 in the as-homogenized, as-MDFed alloys for 1, 3 and 6 passes, respectively, implying that the increase in MDF pass improves the strain-independent damping capacity. The damping capacities are linearly increased in all of the samples, when the strain amplitude is higher than this critical value (G-L curves, Fig. 9b). Moreover, the damping capacity is quite deviated from linear relation with strain amplitude, once it is beyond $2.5 \times 10^{-4}$, implying that the probable microstructure evolutions induced by high strain amplitude will influence the damping behaviors of ZK60 alloys. The maximum damping values are measured as $0.0090,0.0106$, 0.0114 and 0.0139 in the as-homogenized, as-MDFed alloys for 1, 3 and 6 passes, respectively. As shown in Fig. 9c, temperature-dependent damping curves of the samples exhibit two obvious peaks at $100-150{ }^{\circ} \mathrm{C}$ (defined as $\mathrm{P}_{1}$ ) and $250-350{ }^{\circ} \mathrm{C}$ (defined as $\mathrm{P}_{2}$ ), respectively. Especially, the as-MDFed alloy after 6 passes represents the (a)

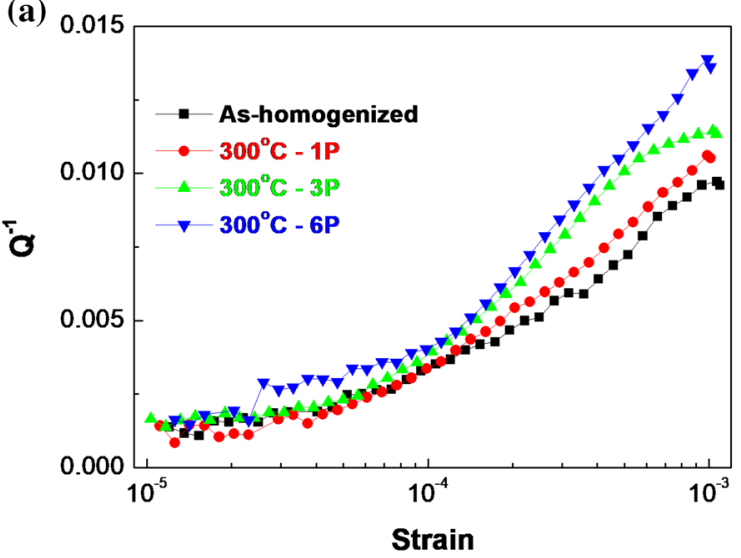

(b)

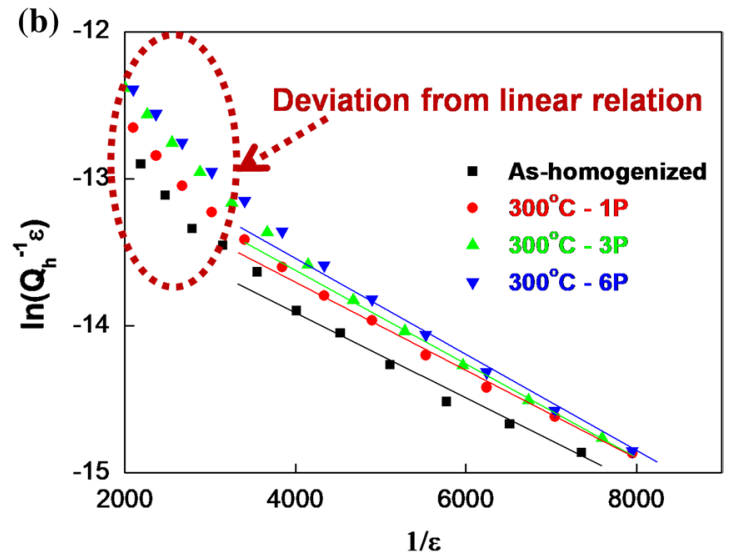

(c)

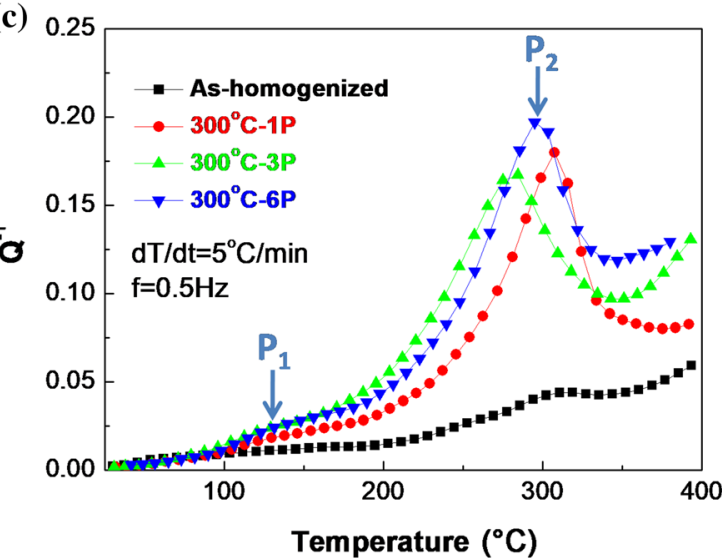

Fig. 9 Damping behaviors of the as-MDFed alloys: a strain amplitude versus damping curves, b G-L plots, c temperature-dependent damping capacity 
most excellent damping capacity, compared with that of as-homogenized alloy. It is visible that the MDF processing results in a simultaneously improvement of mechanical properties and damping capacities of ZK60 alloys.

\section{Discussion}

Generally speaking, the mechanical properties and damping capacities of $\mathrm{Mg}$ alloys are mainly influenced by microstructure evolution and texture modification. In the current study, the repeating MDF deformation results in the obvious grain refinement through the dynamic recrystallization process, which provides an effective approach of achieving the improvement of mechanical properties and damping capacities of ZK60 alloys in the future. The detailed mechanisms are further discussed as follows.

\subsection{Mechanisms of Microstructure and Texture Evolution}

Although the elevated-temperature processing can effectively promote the activation of non-basal slip systems in $\mathrm{Mg}$ alloys and improve their plastic formation ability to some degree, the twinning behaviors are often observed, in order to coordinate the homogenous deformation [29]. In this study, the average grain size in the as-homogenized alloy is calculated as $\sim 200 \mu \mathrm{m}$, and the grain-boundary sliding is difficult to occur. Therefore, the tension twinning can be activated during initial MDF processing, due to its ultra-low critical resolved shear stress, compared with that of $\{10 \overline{1} 1\}\langle 10 \overline{1} 2\rangle$ contraction twins [30, 31]. During the initial stage of MDF processing (1-3 passes), the dynamic recrystallization is uncompleted, because the accumulated strains are not enough. Moreover, many LAGBs can be observed within the fine-grained regions (Fig. 4a), implying that a continuous dynamic recrystallization (CDRX) process occurs (there exists a gradual transformation from LAGBs to HAGBs) [32, 33]. Meanwhile, the tension twinning can be activated within some coarse unDRX grains, which contribute to the discontinuous dynamic recrystallization (DDRX), representing many fine grains observed within these twins (shown by blue arrows in Fig. 4c). With further MDF processing, the DRX region is gradually enlarged, exhibiting a homogenous equiaxed grain structure, which is ascribed to the CDRX process. The twinning behavior is hindered because of grain refinement, and therefore the CDRX process can be proved as the main deformation mechanism, with its characteristic transition from LAGBs to HAGBs (Fig. 5). In addition, the $\mathrm{Zn}$ elements are supersaturated in the as-homogenized alloy. Therefore, the precipitation of $\mathrm{MgZn}_{2}$ phase occurs during the reduplicative MDF process
(Figs. 2 and 3), leading to the homogeneous distribution of fine precipitate particles.

The specific texture evolution behaviors during the MDF processing are related to the deformation mechanisms, including the dislocation slip, twinning activation and recrystallization. In this study, the texture intensity is remarkably increased during the initial MDF processing (1-2 passes), because many unDRX coarse grains are deformed through dislocation slip and twinning activation. For the ZK60 alloy with $c / a<\sqrt{3}$, it can be widely accepted that the activation of basal slip system will result in the $c$ axis parallel to compression or forging direction, exhibiting a typical basal texture with (0001) planes perpendicular to $\mathrm{FD}[34,35]$. Meanwhile, some basal poles can be rotated approximately $\sim 86^{\circ}$ from the center of (0001) pole figure towards the compression direction, due to the occurrence of tension twins. Therefore, the as-MDFed alloy represents a bimodal texture evolution ( $A$ and $B$ types) in Fig. $6 \mathrm{a}$, which is derived from basal slip and twinning behavior. Moreover, this double-peak distribution phenomenon cannot be observed in the global texture analysis, because of the low volume fraction of tension twins. In contrast, a reversed phenomenon can be observed with further deformation (3-6 passes), the texture intensity is gradually decreased, which may be related to the recrystallization process [36, 37]. More importantly, a non-basal texture component has been gradually formed, because the grain refinement is beneficial to the activation of prismatic or pyramidal slip systems. Furthermore, the particle stimulated nucleation (PSN) from dynamic precipitation of fine $\mathrm{MgZn}_{2}$ phase favorably leads to more randomly oriented nuclei, which contributes to the texture weakening effect $[38,39]$.

\subsection{Improvement Mechanisms of Mechanical Properties and Damping Capacities}

Room-temperature deformation behaviors of $\mathrm{Mg}$ alloys are mainly determined by both basal slip and twinning activation, and therefore the improved mechanical property after MDF processing is related to the grain refinement and texture modification. In this study, the TYS values are almost linearly increased in the as-MDFed alloys after 1, 2 and 3 passes, because the enhanced grain refinement leads to an intensive grain boundary strengthening effect, according to the classical Hall-Petch relation [40]. With further MDF processing, the TYS is decreased to some degree, which is attributed to the weakening effect of basal texture. In order to quantitatively analyze the influence of texture modification on the yield strength, Fig. 10 provides the average Schmid factor (SF) of the as-MDFed alloys after different passes. The lowest SF value appears in the as-MDFed alloy for 1 pass, exhibiting an intensive texture strengthening effect. However, the existence of many coarse unDRX 

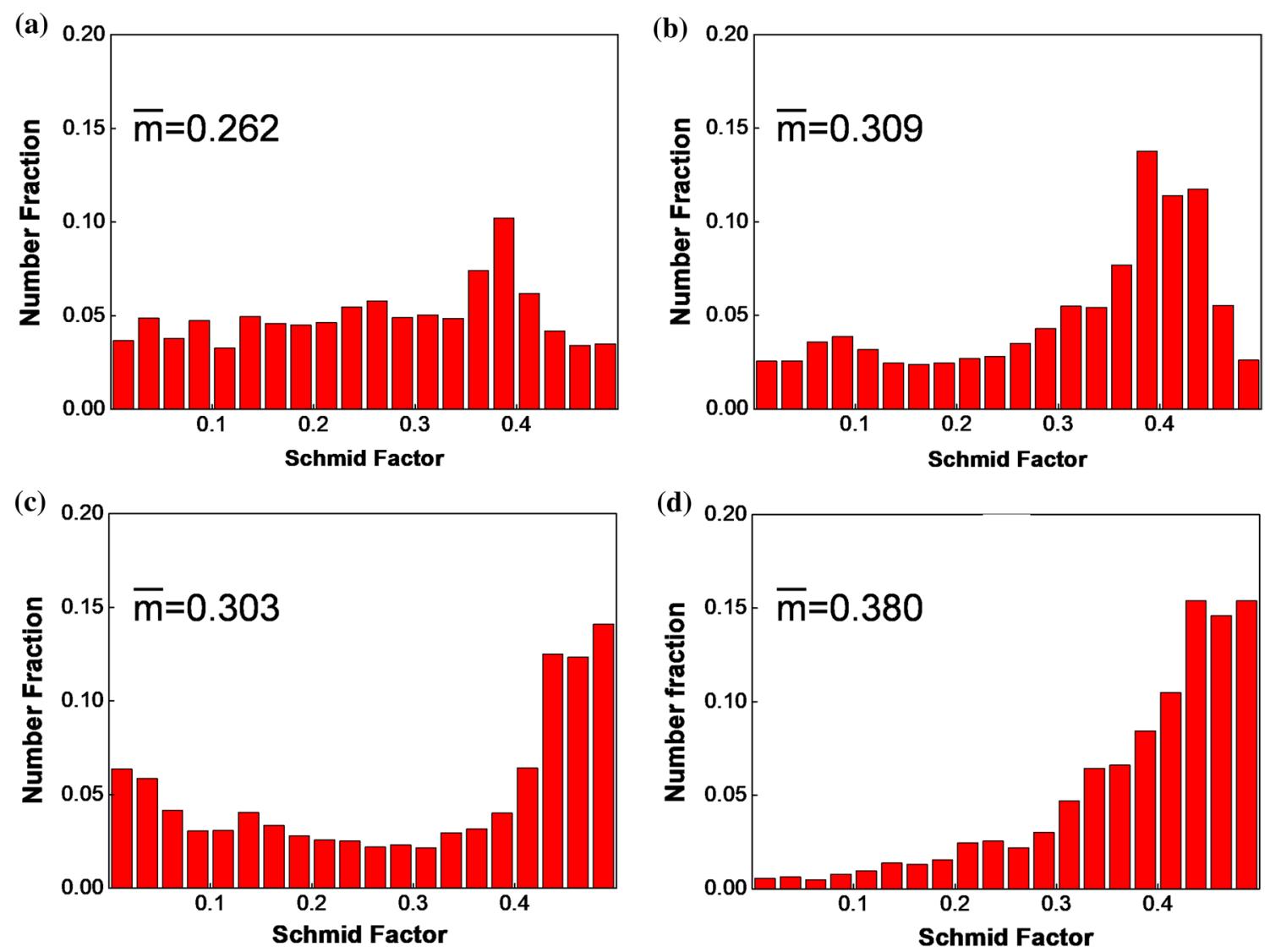

Fig. 10 Schmid factor distribution of the as-MDFed alloy for a 1 pass, $\mathbf{b} 2$ passes, $\mathbf{c} 3$ passes $\mathbf{d} 6$ passes

grains severely hinders the improvement of yield strength. For the as-MDFed alloys for 3 passes, the grain refinement has become the main strengthening mechanism, leading to the highest TYS value. During the MDF processing from 3 to 6 passes, the grain refinement effect is gradually weakened, because the DRX process is almost completed, and the increased SF value from the non-basal texture component results in the decrease in TYS. The competitive relation between the grain boundary and texture strengthening effects finally determines the different evolutions of the yield strength in the as-MDFed alloys. Furthermore, the dynamic precipitations of fine $\mathrm{MgZn}_{2}$ particles also contribute to the increased yield strength of the as-MDFed alloys.

It is worth noting that the ductility of ZK60 alloy is remarkably improved, and the fracture inspection is shown in Fig. 11. Some faceted morphologies and hierarchical structures (red arrows in Fig. 11a and b) can be observed on the fracture surface of the as-MDFed alloys for 1 and 2 passes, implying a cleavage fracture mechanism. With increasing MDF passes, the existences of many dimple structures in Fig. 11c and d (shown by blue arrows) prove the typical ductile-fracture characteristic. The microstructure becomes more homogenous (fine equiaxed grains) with increasing MDF strains, and the volume fraction of unDRX coarse grain is remarkably decreased, which can effectively restrict the heterogeneous deformation and improve the ductility of the as-MDFed alloy. The detailed strengthening mechanisms during the MDF processing are summarized in Fig. 12a.

The damping capacities $\left(Q_{\text {total }}^{-1}\right)$ of $\mathrm{Mg}$ alloys are usually divided into the strain-independent and the strain-dependent parts [41], which can be described as Eq. (1):

$Q_{\text {total }}^{-1}=Q_{0}^{-1}+Q_{h}^{-1}$.

At low strain amplitude, the damping mechanism can be interpreted through the dislocation theory developed by Granato and Lücke (G-L model) [42]. According to G-L theory, the strain amplitude-independent damping capacity $\left(Q_{0}^{-1}\right)$ is mainly related to the mobility of dislocations between the weak pinning points (vacancy or solute atoms), which is proportional to the dislocation density $(\rho)$ and the mean length of the dislocations between the weak pinning points $(l)$, respectively. The strain amplitude damping capacity $\left(Q_{h}^{-1}\right)$ is expressed as Eq. (2), where $C_{1}$ and $C_{2}$ are constants which are functions of dislocation density and distance between 

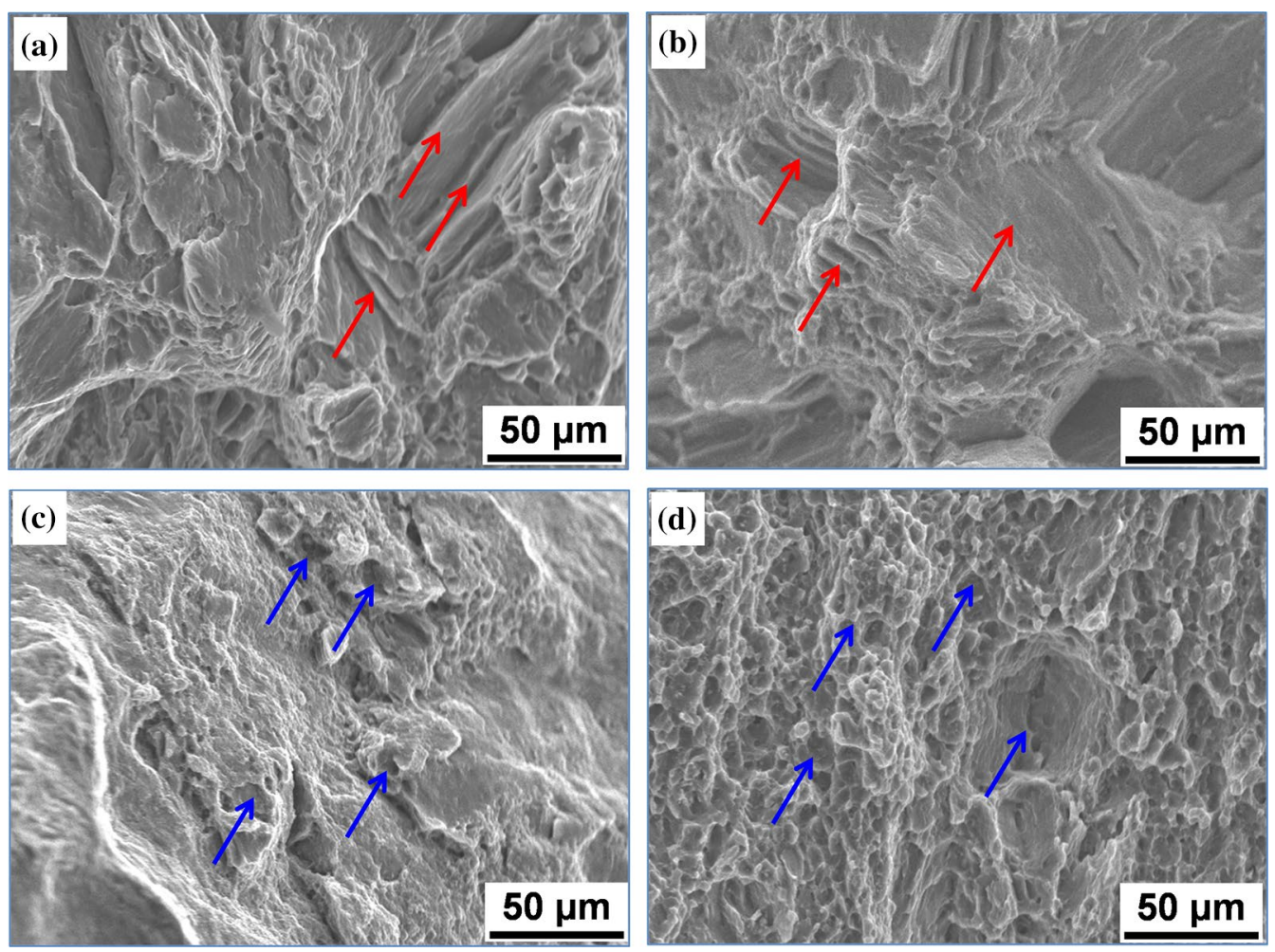

Fig. 11 Fracture morphologies of the as-MDFed alloys for $\mathbf{a} 1$ pass, $\mathbf{b} 2$ passes, $\mathbf{c} 3$ passes $\mathbf{d} 6$ passes

the pinning points $\left(K_{1}\right.$ and $K_{2}$ are the constants, and $L$ is the dislocation distance between the strong pinning points, such as dislocation nets, precipitate particles, sub-grain or grain boundaries) [43, 44].

$Q_{h}^{-1}=\left(C_{1} / \varepsilon\right) \exp \left(-C_{2} / \varepsilon\right)$.

$C_{1}=\frac{K_{1} \rho L^{3}}{l^{2}}$

$C_{2}=\frac{K_{2}}{l}$

In the current study, the MDF processing increases the dislocation density, and therefore the strain-independent damping capacity is improved to some degree in the as-MDFed alloys for 3 and 6 passes (Fig. 9a). However, the $Q_{0}^{-1}$ value in the 1-pass sample is almost the same with that in the as-homogenized alloy, because the initial MDF process often increases the number of vacancies (as weak pinning points) and decreases the mean length of the dislocations ( $l$ value). When the strain amplitude is beyond the critical value $\left(\sim 3.0 \times 10^{-5}\right)$, the strain-dependent damping capacity is related to the breakaway of dislocation segments from the weak pinning points, which can reversibly slide between the strong pinning points. According to the G-L model, the $\ln \left(C_{1}\right)$ and $C_{2}$ values are determined by the intercepts and slopes of the samples in Fig. 9b. Inspection of Eq. (3), it can be concluded that the increased vacancy density after MDF processing remarkably reduces the $l$ value, which can effectively increase the $\ln \left(C_{1}\right)$ value. The number of dislocationnet structures (as the strong pinning points) and $L$ value are gradually decreased with further MDF processing, representing the highest $C_{1}$ value in the 6-passes sample. More importantly, the increase in mobile dislocation leads to the large sweep areas and contributes to the improved damping capacity of the as-MDFed alloy, and corresponding damping mechanism is demonstrated in Fig. $12 \mathrm{~b}$. The slope $\left(C_{2}\right.$ value $)$ is gradually increased with increasing MDF passes to a certain degree, because the formation of additional vacancy leads to the decreased of $l$ value. When the strain amplitude is above $2.5 \times 10^{-4}$, the deviation phenomenon from the straight line occurs. The G-L model is no longer applicable, due to the appearance of micro-plastic deformation [41, 45], which cannot be interpreted by dislocation theory. The nonbasal texture in the as-MDFed alloy for 6 pass is favorable for basal slip, which effectively improves the vibration mobility between the strong pinning points and leads to the highest damping capacity. More detailed works about the texture evolution and vacancy distribution on the damping behavior of the as-MDFed ZK60 alloy are undergoing. 
$\begin{array}{lll}\text { - Grain orientation } & - \text { Precipitate particle } & \text { Grain boundaries } \\ * & \text { Strong pinning particle } & \text { ESweep areas of dislocation } \\ \text { Mobile dislocation }\end{array}$

\section{As-homogenized alloy}
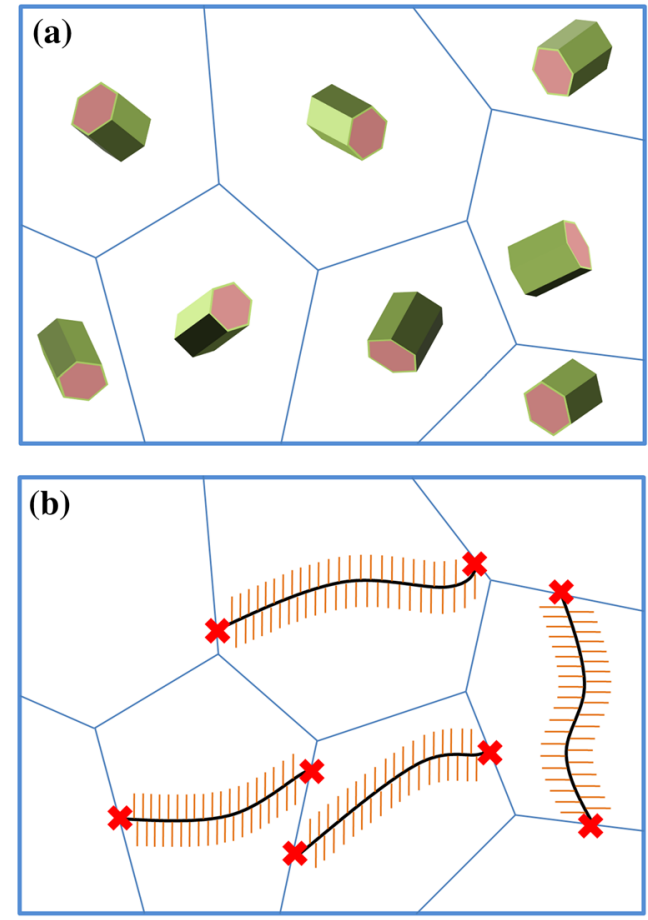

As-MDFed alloy
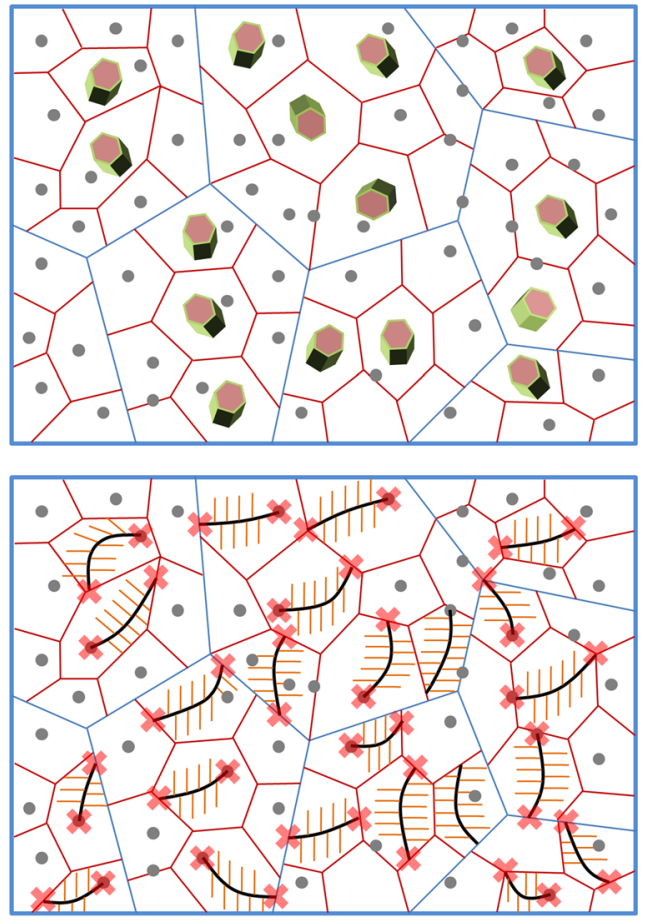

Fig. 12 Schematic diagrams of the a strengthening $\mathbf{b}$ damping mechanisms for the ZK60 alloys before and after MDF process

In addition, the elevated-temperature damping behaviors have been remarkably improved in the as-MDFed alloys. Actually, the grain boundaries often exhibit a viscous feature, and thus the $P_{1}$ damping peak around $100-150{ }^{\circ} \mathrm{C}$ (Fig. 9) is derived from the viscous slide of the grain boundaries, and whose value can be determined by the resistance to the grain boundary sliding and the sliding distance [46]. The increased volume fraction of grain boundaries from grain refinement after MDF processing effectively hinders the viscous slide behaviors and improves the damping capacity, which is in agreement with the previous studies $[44,46]$. The evident $P_{2}$ damping peak in the as-MDFed alloy can be ascribed to the activation of grain boundaries because of grain refinement, which experience a typical transition to the weak pinning points at $250-350^{\circ} \mathrm{C}$, leading to the high dislocation mobility and greatly improving the damping capacities.

\section{Conclusions}

In this study, the mechanical properties and damping capacities of ZK60 alloys have been simultaneously improved, through a multi-pass MDF processing. The microstructure and texture evolution during the reduplicative MDF process are systematically investigated, and the corresponding mechanisms are further revealed, which will open a new window for the design and fabrication of high-performance $\mathrm{Mg}$ alloys by SPD techniques. The main conclusions are summarized as follows:

1. The activation of tension twinning induces the discontinuous dynamic recrystallization behaviors of the ashomogenized ZK60 alloy, leading to a bimodal grain size distribution. With increasing accumulated strains, a continuous dynamic recrystallization occurs, which accomplishes a homogenous fine-grained microstructure.

2. The double texture components appear in the as-MDFed alloy for 1 pass, due to the $86.3^{\circ}$ rotation during the twinning process. Wither further MDF processing, the conventional basal texture is remarkably weakened and gradually replaced by a non-basal texture, with the (0001) planes inclined $60^{\circ}-70^{\circ}$ to $\mathrm{FD}$ and $10^{\circ}-20^{\circ}$ to TD.

3. The combination of grain boundary strengthening, texture modification and dynamic precipitation of $\mathrm{MgZn}_{2}$ 
particles contributes to the improvement of the yield strength in the as-MDFed alloys. The homogenous microstructure of fine equiaxed grains effectively restricts the heterogeneous deformation, leading to the excellent ductility.

4. The strain-dependent damping capacity is remarkably improved, because a large number of dislocations formed in the as-MDF alloy effectively increase their large sweep areas. The grain refinement improves the high dislocation mobility, leading to the excellent damping capacity at elevated temperature.

Acknowledgements This work was financially supported by the National Natural Science Foundation of China (No. 51771178), the Shanxi Provincial Key Research and Development Project (Nos. 2020KWZ-007, 2018ZDXM-GY-149) and the Natural Science Foundation of Jilin Province (No. 20180414016GH).

\section{References}

[1] J.H. Wang, L. Xu, R.Z. Wu, J. Feng, J.H. Zhang, L.G. Hou, M.L. Zhang, Acta Metall. Sin. -Engl. Lett. 33, 490 (2020)

[2] W. Wang, P. Han, P. Peng, T. Zhang, Q. Liu, S.N. Yuan, L.Y. Huang, H.L. Yu, K. Qiao, K.S. Wang, Acta Metall. Sin. Engl. Lett. 33, 43 (2020)

[3] K. Munir, J. Lin, C. Wen, P.F.A. Wright, Y. Li, ActaBiomater. 102, 493 (2020)

[4] Q. Yang, A.K. Ghosh, Acta Mater. 54, 5159 (2006)

[5] L.B. Tong, J.H. Chu, W.T. Sun, Z.H. Jiang, D.N. Zou, K.S. Wang, S. Kamado, M.Y. Zheng, J. Alloys Compd. 825, 153942 (2020)

[6] H. Pan, R. Kang, J. Li, H. Xie, Z. Zeng, Q. Huang, C. Yang, Y. Ren, G. Qin, Acta Mater. 186, 278 (2020)

[7] F. Pan, J. Mao, G. Zhang, A. Tang, J. She, Prog. Nat. Sci. Mater. 26, 630 (2016)

[8] B. Langelier, A.M. Nasiri, S.Y. Lee, M.A. Gharghouri, S. Esmaeili, Mater. Sci. Eng. A 620, 76 (2015)

[9] S.Y. Jin, H.Y. Liu, R.Z. Wu, F. Zhong, L.G. Hou, J.H. Zhang, Mater. Sci. Eng. A 788, 139611 (2020)

[10] W. Xiao, M.A. Easton, M.S. Dargusch, S. Zhu, M.A. Gibsonc, Mater. Sci. Eng. A 539, 177 (2012)

[11] J. Go, J.H. Lee, H. Yu, S.H. Park, J. Alloys Compd. 821, 153442 (2020)

[12] Y. Cui, J. Li, Y. Li, Y. Koizumi, A. Chiba, Mater. Sci. Eng. A 708, 104 (2017)

[13] K. Nishiyama, R. Matsui, Y. Ikeda, S. Niwa, T. Sakaguchi, J. Alloy. Compd. 355, 22 (2003)

[14] J.F. Wang, S. Li, Z.S. Wu, H.B. Wang, S.Q. Gao, F.S. Pan, J. Alloy. Compd. 729, 545 (2017)
[15] H. Miura, T. Maruoka, X. Yang, J.J. Jonas, Scr. Mater. 66, 49 (2012)

[16] C. Wang, A. Ma, J. Sun, H. Liu, H. Huang, Z. Yang, J. Jiang, J. Alloy. Compd. 793, 259 (2019)

[17] W.T. Sun, X.G. Qiao, M.Y. Zheng, X.J. Zhao, H.W. Chen, N. Gao, M.J. Starink, Scr. Mater. 155, 21 (2018)

[18] L. Hou, T. Wang, R. Wu, J. Zhang, M. Zhang, A. Dong, B. Sun, S. Betsofen, B. Krit, J. Mater. Sci. Technol. 34, 317 (2018)

[19] B. Dong, Z. Zhang, J. Yu, X. Che, M. Meng, J. Zhang, J. Alloy. Compd. 823, 153776 (2020)

[20] X. Xia, Q. Chen, Z. Zhao, M. Ma, X. Li, K. Zhang, J. Alloy. Compd. 623, 62 (2015)

[21] F.F. Cao, K.K. Deng, K.B. Nie, J.W. Kang, H.Y. Niu, J. Alloy. Compd. 770, 1208 (2019)

[22] A. Jamali, R. Mahmudi, Mater. Sci. Eng. A 752, 55 (2019)

[23] L. Yu, H. Yan, J. Chen, W. Xia, B. Su, M. Song, Mater. Sci. Eng. A 772, 138707 (2020)

[24] S.H. Kim, S.H. Park, J. Alloy. Compd. 835, 155257 (2020)

[25] X.D. Li, H.T. Ma, Z.H. Dai, Y.C. Qian, L.J. Hu, Y.P. Xie, J. Alloy. Compd 696, 109 (2017)

[26] K. Yan, J. Bai, H. Liu, Z.Y. Jin, J. Magnes. Alloy. 5, 336 (2017)

[27] S.M.H. Karparvarfard, S.K. Shaha, S.B. Behravesh, H. Jahed, B.W. Williams, J. Mater. Sci. Technol. 33, 907 (2017)

[28] S.M.H. Karparvarfard, S.K. Shaha, S.B. Behravesh, H. Jahed, B.W. Williams, Int. J. Fatigue 118, 282 (2019)

[29] T. Liu, Q. Yang, N. Guo, Y. Lu, B. Song, J. Magnes. Alloy. 8, 66 (2020)

[30] F. Mokdad, D.L. Chen, D.Y. Li, Mater. Des. 119, 376 (2017)

[31] J.H. Zhang, S.J. Liu, R.Z. Wu, L.G. Hou, M.L. Zhang, J. Magnes. Alloy. 6, 277 (2018)

[32] G. Zhou, Z. Li, D. Li, Y. Peng, H. Wang, P.D. Wu, Mater. Sci. Eng. A 730, 438 (2018)

[33] A. Galiyev, R. Kaibyshev, G. Gottstein, Acta Mater. 49, 1199 (2001)

[34] S.R. Agnew, M.H. Yoo, C.N. Tomé, Acta Mater. 49, 4277 (2001)

[35] H. Ding, L. Liu, S. Kamado, W. Ding, Y. Kojima, Mater. Sci. Eng. A 452-453, 503 (2007)

[36] Y.Z. Du, M.Y. Zheng, Y.F. Ge, B.L. Jiang, M.J. Shen, Mater. Charact. 145, 501 (2018)

[37] Y. Jiang, L. Guan, G. Tang, J. Alloy. Compd. 656, 272 (2016)

[38] E.A. Ball, P.B. Prangnell, Scr. Metall. Mater. 31, 111 (1994)

[39] H. Esmaeilpour, A. Zarei-Hanzaki, N. Eftekhari, H.R. Abedi, M.R. GhandehariFerdowsi, Mater. Sci. Eng. A 778, 139021 (2020)

[40] N.J. Petch, J. Iron Steel Inst. 174, 25 (1953)

[41] G.D. Fan, M.Y. Zheng, X.S. Hu, K. Wu, W.M. Gan, H.G. Brokmeier, Mater. Sci. Eng. A 561, 100 (2013)

[42] A. Granato, K. Lücke, J. Appl. Phys. 27, 583 (1956)

[43] X. Zhou, H. Yan, J. Chen, W. Xia, B. Su, L. Yu, W. Huang, M. Song, J. Alloy. Compd. 819, 152961 (2020)

[44] Y.T. Tang, C. Zhang, L.B. Ren, W. Yang, D.D. Yin, G.H. Huang, H. Zhou, Y.B. Zhang, J. Magnes. Alloy. 7, 522 (2019)

[45] C.F. Burdett, Philos. Mag. 24, 1459 (1971)

[46] T. Kê, Phys. Rev. 71, 533 (1947) 